\title{
Dogs and Cats and Their Relationships with Humans as Depicted in Picture Books
}

\author{
Hinako Shimatani, Naoko Koda* \\ Graduate School of Agriculture, Tokyo University of Agriculture and Technology, Tokyo, Japan
}

Email address:

koda@cc.tuat.ac.jp (N. Koda)

${ }^{*}$ Corresponding author

\section{To cite this article:}

Hinako Shimatani, Naoko Koda. Dogs and Cats and Their Relationships with Humans as Depicted in Picture Books. International Journal of Literature and Arts. Vol. 9, No. 2, 2021, pp. 63-69. doi: 10.11648/j.ijla.20210902.13

Received: February 25, 2021; Accepted: March 23, 2021; Published: April 13, 2021

\begin{abstract}
Attitudes toward animals are influenced by childhood experiences with animals. One source of such experiences is provided by picture books. Because the representations of animals in picture books affect attitudes toward animals, it is important to examine how animals are depicted in picture books in order to improve human-animal interactions. Since dogs and cats are particularly familiar to children, it is easy for children to apply representations in picture books to real dogs and cats. This study quantitatively investigated how dogs and cats are depicted in picture books. Several elements were extracted from the pictures in the picture books and their state was recorded. The analysis included comparisons of depictions of dogs and cats, human presence and absence, and story settings in 2040 picture books that contained depictions of dogs or cats. The results revealed that dogs and cats were anthropomorphized or humanized much less often in picture books in which humans appeared than in those in which humans did not appear. Dogs were often drawn on the ground outside, and cats were often shown in elevated positions or indoors. For dogs, there were many depictions of walks, often in urban settings. In general, the analysis of the depictions suggests that children may feel boundary between human and dog/cat based on the picture books. The analysis of the walking scenes suggests that the reality of dogs may be conveyed to children. In addition, the analysis of the positions of dogs and cats suggests that traditional representation of them and their relationships with humans may be conveyed to children in such books.
\end{abstract}

Keywords: Anthropomorphism, Cat, Dog, Human-animal Interaction, Picture Book

\section{Introduction}

Childhood experiences with animals affect attitudes and behaviors toward animals, and the effects of these early experiences persist over time [1-3]. Therefore, in order to improve human-animal interactions, it is important to improve childhood experiences with animals.

Children are interested in animals from a very young age [4] Infants under the age of 1 year can discriminate between living and inanimate objects $[5,6]$. Children encounter and recognize animals in a variety of situations. These encounters can be both direct and indirect. Direct examples include encounters at zoos, in the local community, and in husbandry at home or school. Indirect examples include encounters through television and children's books. Many studies have investigated the effects of direct experience with animals on perception of and attitude toward animals $[2,7,8]$, while less attention has been paid to indirect animal experiences. However, indirect experiences occur through media that children are exposed to daily. This is especially true for picture books, which have a great influence on children. Urban children tend to lack direct experience with a variety of animals and have been found to be more susceptible to media such as picture books when acquiring knowledge and representations of animals [9]. Thus attempts to build better relationships between children and animals should not ignore the role of picture books.

Children are exposed to picture books from babyhood. Characteristics of picture books have been examined for appropriateness to different developmental stages in promoting child development [10-12]. Picture books are regarded as important in the field of childcare and early child education, and their effects on language development have been particularly noted $[13,14]$. A variety of other learning benefits have also been confirmed, including biological and physical knowledge and concepts, problem solving, and moral learning; children are expected to learn such matters from picture books and apply 
them to real life [15]. Thus, animals described in picture books can affect not only children's biological knowledge but also the way they value and conceptualize animals.

Previous studies of animals depicted in picture books investigated the effects of anthropomorphism on learning [9, 16-18], the roles of animals from the perspective of educational anthropology and educational philosophy [19], and the ways animal habitats and morphology are expressed [20]. Research on environmental and scientific picture books has also examined the number of books in which animals appear and how they are described [21-25]. These studies have pointed out that animals in picture books have both positive and negative effects on children's knowledge and representations of animals, and on their relationships with animals.

Animals in picture books and characters' behavior toward animals can affect the ways children form representations of animals and interact with them. Therefore, in order to build better relationships between children and animals, it is necessary to clarify the representations of animals that children may be exposed to as they read picture books. Although there have been a number of qualitative studies of the depiction of animals and their relationships with humans in picture books, few detailed quantitative analyses are available [20, 26].

Of the domesticated animals, dogs and cats live with children in large numbers, and children have a higher level of empathy for dogs and cats than for other animals [27]. Because dogs and cats have close relationships to humans in daily life and are familiar to children, children should readily attribute the representation of dogs and cats in picture books to those in the real world.

\section{Purpose of This Study}

The purpose of this study was to examine how dogs and cats and their relationships with humans are depicted in picture books by extracting relevant elements from pictures and analyzing them quantitatively.

\section{Methods}

We surveyed picture books with pictures of dogs or cats, that were found in the picture book corner of the open shelves of a city library in a residential area in Tokyo, Japan. The library was large and familiar to the citizens. The number of children's books, including picture books, was 144,215. Of the 4072 picture books in Japanese on the open shelves, 2040 books included pictures of dogs or cats and were used for analysis. The survey was conducted from 2018 to 2019. Ethical approval was not required because this study was a survey of published literature.

For each picture book, scenes were identified as describing situations that occurred at different times in the story. In some picture books, there was only one scene per page, and in other cases, there were several scenes per page. When several dogs or cats were depicted in the same scene, one dog and one cat that were shown closest to a human were recorded. In order to examine how dogs and cats are depicted in picture books, elements were identified and extracted from all applicable scenes in each picture book, and their states were recorded; these are summarized in Table 1. First, each character was identified as dog, cat, or human. With reference to McCrindle and Odendaal [26], the depiction types of dog/cat represented three states: real, a state in which the dog/cat had a realistic appearance; humanized, a state in which the dog/cat had a realistic appearance but spoke or thought like a human; and anthropomorphic, a state in which the dog/cat walked on its hind legs, thus clearly differentiating it from a real animal. Similarly, the role of dog/cat in the story was classified as a protagonist who was in the main flow of the story, as a supporting character who was not in the main flow of the story but appeared in the text, or as a background character who did not appear in the text but only in the pictures. The elements of position and collar were recorded only for picture books that satisfied all five of the following setting criteria for each scene in which dogs or cats and humans were depicted: being a story, having sentences, depicting dogs or cats in the main story, lacking anthropomorphic dogs/cats, and depicting a human in the same scene in which a dog/cat was depicted. Being a story was established as a criterion to exclude picture books for infants, non-narrative picture books about words and poetry, picture books whose main purpose was intellectual education (such as science concepts), pop-up books, and picture books with collections of short stories. Lack of anthropomorphism was established as a criterion to confirm the dog/cat as an animal so that their relationships with humans could be recorded. In other words, this criterion attempted to prevent readers from interpreting the anthropomorphized dog/cat as a human-like $\mathrm{dog} / \mathrm{cat}$ and its relationships with humans as relationships between two humans. When it was difficult to determine the classification, two judges consulted. If a determination still could not be made, a classification of "unclear" was recorded.

Chi-square tests and Fisher's exact probability tests were applied in the data analysis, and post-hoc analyses were performed using residual analysis and the Ryan method.

Table 1. Elements surveyed and their classifications.

\begin{tabular}{ll}
\hline Element & Classification \\
\hline Character & Dog/Cat/Human \\
$\begin{array}{l}\text { Depiction type of dog/cat } \\
\text { Role of dog/cat }\end{array}$ & $\begin{array}{l}\text { Real/Humanized/Anthropomorphic } \\
\text { Protagonist/Supporting character/Background character } \\
\text { Story setting }\end{array}$ \\
$\begin{array}{l}\text { Urban/Rural/Both } \\
\text { Number of pictures of walking }\end{array}$ & \\
Collar & On ground/On roof/On wall/On chair/On floor inside/In human arms/Other \\
\hline
\end{tabular}




\section{Results}

Of the picture books with dogs or cats, $34 \%$ had only dogs, $25 \%$ had only cats, and $41 \%$ had both dogs and cats. Position and collar were recorded in 781 books with 4086 scenes. In a preliminary survey, no significant differences were found for any elements with respect to the periods of publication (1844-2018). Therefore, year of publication was not considered in the main analysis. Results are shown for those items for which the effect size was at least moderate [28] and significant differences were confirmed, and also for those items for which noticeable differences were confirmed based on the frequencies.

\subsection{Depiction Type and Human Presence}

Table 2 shows the distribution of picture books in terms of depiction type of dogs and presence or absence of humans. A chi-square test indicated a significant difference $\left(\chi^{2}\right.$ (3, $n=1595)=243.83, p<0.001, V=0.39)$, with residual analysis revealing that the real type of dog appeared significantly more in picture books with humans and less in picture books without humans $(p<0.001)$. On the other hand, humanized dogs and anthropomorphic dogs appeared significantly less often with humans and more without humans (humanized, $p$ $<0.001$; anthropomorphic, $p<0.05)$.

Table 2. Distribution of picture books by depiction type of dogs and presence or absence of humans in the book.

\begin{tabular}{llll}
\hline \multirow{2}{*}{ Depiction type of dog } & \multicolumn{2}{l}{ Human } & \multirow{2}{*}{ Total } \\
\cline { 2 - 3 } & Presence & Absence & \\
\hline Real & $1136(81)^{*}$ & $70(36)$ & $1206(76)$ \\
Humanized & $112(8)$ & $26(13)$ & $138(9)$ \\
Anthropomorphic & $126(9)$ & $92(46)$ & $218(14)$ \\
Unclear & $22(2)$ & $11(6)$ & $33(2)$ \\
Total & $1396(100)$ & $199(100)$ & $1595(100)$ \\
\hline
\end{tabular}

${ }^{*}$ Numbers in parentheses are percentages.

Table 3 shows the distribution of picture books in terms of depiction type of cats and presence or absence of humans in the book. A chi-square test indicated a significant difference $\left(\chi^{2}(3, n=1408)=134.03, p<0.001, V=0.31\right)$, with residual analysis demonstrating that, as with dogs, the real type of cats appeared significantly more often in picture books with humans and less in books without humans $(p<0.001)$, and humanized cats and anthropomorphic cats appeared significantly less often with humans and more without humans (humanized, $p<0.05$; anthropomorphic, $p<0.001$ ).

Table 3. Distribution of picture books by depiction type of cats and presence or absence of humans in the book.

\begin{tabular}{llll}
\hline \multirow{2}{*}{ Depiction type of cat } & \multicolumn{2}{l}{ Human } & \multirow{2}{*}{ Total } \\
\cline { 2 - 3 } & Presence & Absence & \\
\hline Real & $869(73)^{*}$ & $76(35)$ & $945(67)$ \\
Humanized & $124(10)$ & $33(15)$ & $157(11)$ \\
Anthropomorphic & $176(15)$ & $97(45)$ & $273(19)$ \\
Unclear & $23(2)$ & $10(5)$ & $33(2)$ \\
Total & $1192(100)$ & $216(100)$ & $1408(100)$ \\
\hline
\end{tabular}

${ }^{*}$ Numbers in parentheses are percentages.
On the whole, the roles of dogs and cats were not greatly different: dogs and cats were not likely to be the main characters (both 9\%) and they acted supporting characters more frequently (dogs $32 \%$, cats $36 \%$ ), although both appeared most often as background characters (dogs 60\%, cats $56 \%$ ). There were differences in depiction types between dogs and cats according to their roles in the stories. Table 4 shows the distribution of picture books in terms of depiction type of dogs and presence or absence of humans when a dog was the main character. A chi-square test indicated a significant difference $\left(\chi^{2}(3, n=118)=22.399, p<0.001\right.$, $V=0.44)$, and Fisher's exact probability test was also significant $(p<0.001)$. Multiple comparisons using the Ryan method revealed that dogs were frequently humanized when humans were present $(p=0.001)$ but were frequently anthropomorphized when humans were abesnt $(p<0.001)$.

Table 4. Distribution of picture books by depiction type of dogs and presence or absence of humans in the book when a dog was the main character.

\begin{tabular}{llll}
\hline \multirow{2}{*}{ Depiction type of dog } & \multicolumn{2}{l}{ Human } & \multirow{2}{*}{ Total } \\
\cline { 2 - 3 } & Presence & Absence & \\
\hline Real & $22(28)^{*}$ & $6(15)$ & $28(24)$ \\
Humanized & $41(52)$ & $8(21)$ & $49(42)$ \\
Anthropomorphic & $15(19)$ & $23(59)$ & $38(32)$ \\
Unclear & $1(1)$ & $2(5)$ & $3(3)$ \\
Total & $79(100)$ & $39(100)$ & $118(100)$ \\
\hline
\end{tabular}

${ }^{*}$ Numbers in parentheses are percentages.

Table 5 shows the distribution of picture books in terms of depiction type of dogs and presence or absence of humans when a dog was in a background character. A chi-square test indicated a significant difference $\left(\chi^{2}(3, n=821)=215.14, p<\right.$ $0.001, V=0.51)$, and Fisher's exact probability test was also significant $(p<0.001)$. Multiple comparisons using the Ryan method revealed that dogs were frequently depicted as real with humans $(p<0.001)$ but were frequently anthropomorphized without humans $(p<0.001)$.

Table 5. Distribution of picture books by depiction type of dogs and presence or absence of humans in the book when a dog was the background character.

\begin{tabular}{llll}
\hline \multirow{2}{*}{ Depiction type of dog } & \multicolumn{2}{l}{ Human } & \multirow{2}{*}{ Total } \\
\cline { 2 - 3 } & Presence & Absence & \\
\hline Real & $740(96)^{*}$ & $25(50)$ & $765(93)$ \\
Humanized & $2(0)$ & $0(0)$ & $2(0)$ \\
Anthropomorphic & $14(2)$ & $23(46)$ & $37(5)$ \\
Unclear & $15(2)$ & $2(4)$ & $17(2)$ \\
Total & $771(100)$ & $50(100)$ & $821(100)$ \\
\hline
\end{tabular}

* Numbers in parentheses are percentages.

Table 6 shows the distribution of picture books in terms of depiction type of cats and presence or absence of humans in the book when a cat was a background character. As with dogs, a chi-square test indicated a significant difference $\left(\chi^{2}(3\right.$, $n=680)=94.85, p<0.001, V=0.37)$, and Fisher's exact probability test was also significant $(p<0.001)$, and multiple comparisons using the Ryan method revealed that cats were frequently depicted as real with humans $(p<0.001)$ but anthropomorphized without humans $(p<0.001)$. 
Table 6. Distribution of picture books by depiction type of cats and presence or absence of humans in the book when a cat was the background character.

\begin{tabular}{llll}
\hline \multirow{2}{*}{ Depiction type of cat } & \multicolumn{2}{l}{ Human } & \multirow{2}{*}{ Total } \\
\cline { 2 - 3 } & Presence & Absence & \\
\hline Real & $577(92)^{*}$ & $27(53)$ & $604(89)$ \\
Humanized & $5(1)$ & $0(0)$ & $5(1)$ \\
Anthropomorphic & $32(5)$ & $22(43)$ & $54(8)$ \\
Unclear & $15(2)$ & $2(4)$ & $17(2)$ \\
Total & $629(100)$ & $51(100)$ & $680(100)$ \\
\hline
\end{tabular}

* Numbers in parentheses are percentages.

\subsection{Positions of Dogs and Cats}

Table 7 shows the numbers and percentages of scenes for each position in which dogs and cats were depicted. A chi-square test indicated a significant difference $\left(\chi^{2}(6\right.$, $n=4086)=581.24, p<0.001, V=0.38)$, and residual analysis indicated that dogs were frequently shown on the ground $(p<$ $0.001)$, whereas cats were frequently in other positions: on a roof, on top of a wall, on a chair, on the floor inside, in a human's arms, and "other" (all $p \mathrm{~s}<0.001$ ). "Other" positions included on a bed, on windowsills, in trees, and in a car.

Table 7. Number of scenes showing each position of dogs and cats.

\begin{tabular}{llll}
\hline Position & Dog & Cat & Total \\
\hline On ground & $1609(70)^{*}$ & $610(34)$ & $2219(54)$ \\
On roof & $8(0)$ & $56(3)$ & $64(2)$ \\
On wall & $1(0)$ & $54(3)$ & $55(1)$ \\
On chair & $33(1)$ & $53(3)$ & $86(2)$ \\
On floor inside & $434(19)$ & $526(30)$ & $960(23)$ \\
In human arms & $78(3)$ & $177(10)$ & $255(6)$ \\
Other & $147(6)$ & $300(17)$ & $447(11)$ \\
Total & $2310(100)$ & $1776(100)$ & $4086(100)$ \\
\hline
\end{tabular}

${ }^{*}$ Numbers in parentheses are percentages.

\subsection{Walking and Collar}

Three hundred picture books (15\%) depicted walking dogs/cats. Almost all cases (701 scenes) included dogs and only one showed a cat. The story settings that included walking were frequently in urban areas: 453 scenes $(65 \%)$ in urban areas, 60 scenes $(9 \%)$ in rural areas only, 186 scenes $(26 \%)$ in both rural and urban areas, and 3 scenes in unclear areas. The numbers of scenes in which dogs and cats were shown with or without collars are provided in Table 8 . A chi-square test indicated a significant difference $\left(\chi^{2}(1, n=4086)=467.11, p<0.001, \varphi=0.34\right)$. Cats were depicted overwhelmingly often without collars $(p<0.001)$, but dogs were depicted wearing collars relatively often $(p<$ $0.001)$.

Table 8. Number of scenes with dogs and cats with and without collars.

\begin{tabular}{llll}
\hline Collars & Dog & Cat & Total \\
\hline Present & $764(33)$ & $94(5)$ & $858(21)$ \\
Absent & $1546(67)$ & $1682(95)$ & $3228(79)$ \\
Total & $2310(100)$ & $1776(100)$ & $4086(100)$ \\
\hline
\end{tabular}

${ }^{*}$ Numbers in parentheses are percentages.

\section{Discussion}

\subsection{Depiction Type and Human Presence}

This study qualitatively elucidated the features of dogs and cats depicted in picture books in reference to their relationships with humans. As defined here, the animals' morphological distance from humans decreased from real to humanized and then anthropomorphic types. Depictions of humanized and anthropomorphized dogs and cats occurred less frequently when humans were present. Furthermore, even when dogs were the main characters, they remained humanized in the presence of people, and anthropomorphism was more often used without a human presence. Even when dogs and cats were depicted as background characters, the distribution of depiction types depended on the presence or absence of humans, with the real type more common in picture books with humans, and the anthropomorphic type more common in those without humans. This suggests that in picture books in which humans appear, there is resistance to imparting human characteristics to dogs and cats and reducing the mental distance between humans and dogs and cats. Thus the boundary between humans and dogs or cats may be more conscious when humans are depicted. On the other hand, in picture books in which humans did not appear, the animals were sometimes depicted instead of humans. According to Yano [19], there are three main types of picture books that contain only animals: those that are humanistic in nature and simply replace humans with animals, those that use animals to exhibit human characteristics, and those that invite readers to the real world of animals and reject humanism. In order for animals to take the place of humans, they have to be brought closer to humans, and as a result, they must be humanized or anthropomorphized. It is possible that there were many depictions of humanized and anthropomorphized dogs and cats in picture books that did not contain humans because such depictions were intended to replace humans. Thus when dogs and cats take the place of humans, the premise that humans are different from dogs and cats is required, and the boundary between humans and dogs and cats must be clearly recognized.

\subsection{Positions of Dogs and Cats}

There were distinct differences between dogs and cats with respect to the positions in which they were depicted. Dogs were often presented outside on the ground, and cats were often shown inside or in higher places or held in human arms. This was likely the consequence of the roles that dogs and cats have played for humans, and the ways that they have been kept, for a long time. Dogs were the first domesticated animals [29], approximately 12,000 years ago [30]. Dogs were likely first kept for food, as pets and watchdogs, and for cleaning up leftovers, and were later also used for hunting. Eventually dogs were used for sheep herding, transportation, military functions, and so on [29, 31]. Today, they may receive high levels of training for roles such as guide dogs and police dogs. Many of the roles that dogs play are 
conducted outside, which may contribute to the connection between dogs and "outside."

Cats, on the other hand, have a relatively recent domestication history, dating back to ancient Egypt [32], where they were originally domesticated to catch mice in homes around 2,000 BC [33]. Cats then spread from Persia and via India to China. Cats were introduced to Japan in the eighth century to protect Buddhist scriptures from China against mice. Cats were firmly established in the Middle Ages as a countermeasure against mice in the Middle East and Europe and were brought to America after the 16th century $[31,33,34]$. The role of mouse-catching is mainly conducted inside buildings, and this is a plausible reason why cats are associated with "inside." Because the impressions of these traditional roles of dogs and cats are recorded in picture books, child readers may adopt stereotyped representations of dogs and cats.

The fact that many cats are depicted in higher places is likely an expression of cats' habit of climbing to monitor the environment and human approach [35], and it is good for keeping cats to provide structures that can be climbed, such as shelves and raised passages of various heights [32].

Cats were often depicted in human arms. A plausible explanation is that dogs vary greatly in size from small to large, whereas cat breeds are small. This study did not measure the size of dogs and cats in picture books; thus further investigation is needed to explain why cats are more likely to be held than dogs.

\subsection{Walking and Collars}

Dogs, but not cats, were often taken for walks in the picture books. Studies have shown that owning a dog increases walking time [36-40], and walking dogs has a positive effect on human health [41]. On the other hand, owning a cat does not increase the time that the owners walk [39, 40]. It is plausible that depictions of cats being walked were almost absent, while those of dogs were abundant, because the picture books reflected the actual amounts and concepts of walking.

Majority of walking scenes were set in urban areas. A questionnaire survey of dog owners found that more owners in urban than in rural areas regularly walk their dogs [42]. The difference in the frequency of dog walking between urban and rural areas may be related to the presence or absence in the home of a yard where dogs can exercise. Rural dogs tended to be kept in houses with yards and urban dogs in apartments, where yards may be small or absent. Because dogs in rural areas can run freely, dog owners in urban areas may be more likely to walk their dogs [36]. In the present study, houses and buildings were judged as urban or not based on how densely packed they were. Therefore, in the type of scenes that were judged as urban, dogs actually are walked frequently and this was reflected in the depictions.

Collars were often shown on dogs rather than on cats. As mentioned above, dogs are taken for walks, whereas cats are seldom taken for walks. Therefore, dogs often wear collars to attach leashes for walking, but this is unnecessary with cats. This is also reflected in picture books.

\section{Conclusion}

This study identified common representations of dogs and cats that can be found in picture books. The authors and illustrators of the picture books thus may have held the following representation related to dogs and cats.

1. Humans and dogs/cats are different entities and are resistant to being treated in the same way.

2. Dogs are outside, and cats are inside or in high places.

3. Cats are often held by humans.

4. Walking and collars are related to dogs but not to cats.

Children may feel a boundary between human and dog/cat based on the picture books, and traditional representations of dogs and cats and their relationships with humans may be conveyed to children in such books. This may lead children to internalize these attitudes toward animals and the way animals should be handled.

This study focused only on dogs and cats in picture books. Future studies need to investigate the representations of other animals in picture books in order to understand the relationships between children and animals more comprehensively and to improve these relationships. Practical or experimental studies should also clarify the process by which animal picture books affect children's development with respect to human-animal relationships.

\section{Acknowledgements}

The authors thank Ms. S. Mizuta for her assistance.

\section{References}

[1] Kidd, A. H., Kidd, R. M., \& Zasloff, R. L. (1995). Developmental factors in positive attitudes toward zoo animals. Psychological Reports, 76, 71-81.

[2] Paul, E. S., \& Serpell, J. A. (1993). Childhood pet keeping and humane attitudes in young adulthood. Animal Welfare, 2, 321-337.

[3] Fidler, M., Coleman, P., \& Roberts, A. (2000). Empathic response to animal suffering: Societal versus family influence. Anthrozoös, 13, 48-51.

[4] DeLoache, J., Pickard, M. B., \& LoBue, V. (2011). How very young children think about animals. In P. McCardle, S. McCune, J. A. Griffin, \& V. Maholmes (Eds.), How animals affect us: Examining the influence of human-animal interaction on child development and human health (pp. 85-99). Washington, DC: American Psychological Association.

[5] Spelke, E. S., Phillips, A., \& Woodward, A. L. (1995). Infants' knowledge of object motion and human action. In D. Sperber, D. Premack, \& A. J. Premack (Eds.), Causal cognition: A multidisciplinary debate (pp. 44-78). Oxford: Clarendon Press.

[6] Melson, G. F. (2001). Why the wild things are: Animals in the lives of children. Cambridge, MA: Harvard University Press.

[7] Prokop, P., \& Tunnicliffe, S. D. (2009). Effects of having pets at home on children's attitudes toward popular and unpopular animals. Anthrozoös, 23, 21-34. 
[8] Nakajima, Y. (2017). Comparing the effect of animal-rearing education in Japan with conventional animal-assisted education. Frontiers in Veterinary Science, 4, article 85.

[9] Herrmann, P., Waxman, S. R., \& Medin, D. L. (2010). Anthropocentrism is not the first step in children's reasoning about the natural world. Proceedings of the National Academy of Sciences of the United States of America, 107, 9979-9984.

[10] Akita, K. (1994). Encounter with picture books (Ehon tono deai). In N. Uchida (Ed.), Language development psychology: Developmental psychology of reading and speaking (Gengohattatushinrigaku: Yomu kaku hanasu no hattatsusinrigaku) (pp. 26-33). Tokyo: Foundation for the Promotion of the Open University of Japan (in Japanese).

[11] Ikuta, Y., Ishii, M., \& Fujimoto, T. (2013). Basic introduction to picture book (Beshikku ehon nyumon). Kyoto: Minerva Shobo (in Japanese).

[12] Sato, K. (2004). Child development and picture books (Kodomo no hattatsu to ehon). Bulletin of the Faculty of Education Ehime University (Ehime Daigaku Kyouiku Gakubu Kiyo), 51, 29-34.

[13] Ministry of Health, Labour and Welfare. (2017). Childcare guidelines. Retrieved December 31, 2020, from https://www.mhlw.go.jp/file/06-Seisakujouhou-11900000-Koy oukintoujidoukateikyoku/0000160000.pdf.

[14] Ministry of Education, Culture, Sports, Science and Technology. (2017). The national curriculum standard for kindergartens. Retrieved December 31, 2020, from http://www.mext.go.jp/component/a_menu/education/micro_d etail/_icsFiles/afieldfile/2019/09/19/1384661_3_2.pdf.

[15] Strouse, G. A., Nyhout, A., \& Ganea, P. A. (2018). The role of book features in young children's transfer of information from picture books to real-world contexts. Frontiers in Psychology, 9 , article 50 .

[16] Ganea, P. A., Canfield, C. F., Simons-Ghafari, K., \& Chou, T. (2014). Do cavies talk? The effect of anthropomorphic picture books on children's knowledge about animals. Frontiers in Psychology, 5, article 283.

[17] Larsen, N. E., Lee, K., \& Ganea, P. A. (2017). Do storybooks with anthropomorphized animal characters promote prosocial behaviors in young children? Developmental Science, 21, e12590.

[18] Waxman, S. R., Herrmann, P., Woodring, J., \& Medin, D. L. (2014). Humans (really) are animals: Picture-book reading influences 5-year-old urban children's construal of the relation between humans and non-human animals. Frontiers in Psychology, 5, article 172.

[19] Yano, S. (2002). Adventures over animal picture books (Dobutsu ehon o meguru boken). Tokyo: Keiso Shobo. (in Japanese).

[20] Marriott, S. (2002). Red in tooth and claw? Representations of nature in modern picture books. Children's Literature in Education, 33, 175-183.

[21] Deguchi, A., \& Kuwahara, N. (2015). Science picture books for early childhood science education: Through a survey of kindergarten teachers. Bulletin of the Faculty of Education, Utsunomiya University, Section 2, 65, 21-28.

[22] Imamura, M. (2007). Classification of "environmental picture books" and the significance of the processes of "environmental picture books." Environmental Education, 17, 23-35.

[23] Imamura, M. (2013). What do children meet in the picture books concerning forest? Quantitative research on environmental picture books. Annual Report of the Faculty of Education, Gifu University, Humanities and Social Sciences, $61,141-152$.

[24] Imai, K., Kurihara, Y., \& Nojiri, Y. (2010). The study of scientific picture book for infants: From the viewpoint of child's awareness. The Journal of Kawamura Gakuen Woman's University, 21, 19-34.

[25] Kuroda, H., Yamahashi, C., Yamaguchi, E., \& Inagaki, S. (2012). Design of science picture books which young children prefer: A case of "Kagaku-no-Tomo Reprinted Edition." Proceedings of the Annual Meeting of Japan Society for Science Education, 36, 97-98.

[26] McCrindle, C. M. E., \& Odendaal, J. S. J. (1994). Animals in books used for preschool children. Anthrozoös, 7, 135-146.

[27] Rost, D. H., \& Hartmann, A. (1994). Children and their pets. Anthrozoös, 7, 242-254.

[28] Cohen, J. (1988). Statistical power analysis for the behavioral sciences (2nd ed.). Hillsdale, NJ: Lawrence Erlbaum Associates.

[29] Serpell, J. (1995). The domestic dog. Cambridge: Cambridge University Press.

[30] Davis, S. J. M., \& Valla, F. R. (1978). Evidence for domestication of the dog 12,000 years ago in the Natufian of Israel. Nature, 276, 608-610.

[31] Eguchi, Y. (2003). History of animals and humans (Dobutsu to ningen no rekishi). Tokyo: Tsukiji Shokan (in Japanese).

[32] Turner, D. C., \& Bateson, P. (1998). The domestic cat. Cambridge: Cambridge University Press.

[33] Rogers, K. M. (2006). Cat. London, UK: Reaktion Books.

[34] Oishi, T. (2013). The zoology of cats as companion animals. Tokyo: University of Tokyo Press.

[35] James, A. E. (1995). The laboratory cat. Anzccart News, 8, $1-8$.

[36] Brown, S. G., \& Rhodes, R. E. (2006). Relationships among dog ownership and leisure-time walking in western Canadian adults. American Journal of Preventive Medicine, 30, 131-136.

[37] Cutt, H. E., Knuiman, M. W., \& Giles-Corti, B. (2008). Does getting a dog increase recreational walking? International Journal of Behavioral Nutrition and Physical Activity, 5, 17.

[38] Giles-Corti, B., \& Donovan, R. J. (2003). Relative influences of individual, social environmental, and physical environmental correlates of walking. American Journal of Public Health, 93, 1583-1589.

[39] Serpell, J. A. (1990). Evidence for long term effects of pet ownership on human health. In I. H. Burger (Ed.), Waltham Symposium 20: Pets, benefits and practice (pp. 1-7). London: BVA Publications.

[40] Serpell, J. A. (1991). Beneficial effects of pet ownership on some aspects of human health behavior. Journal of the Royal Society of Medicine, 84, 717-720. 
[41] Bauman, A. E., Russell, S. J., Furber, S. E., \& Dobson, A. J. (2001). The epidemiology of dog walking: An unmet need for human and canine health. The Medical Journal of Australia, $175,632-634$.
[42] Baranyiová, E., Holub, A., Tyrlík, M., Janácková, B., \& Ernstová, M. (2005). The influence of urbanization on the behaviour of dogs in the Czech Republic. Acta Veterinaria Brno, 74, 401-409. 